\title{
NEW TECHNOLOGIES AND APPLICATIONS OF MOTION TRACKING IN VIRTUAL REALITY SYSTEMS
}

\author{
Shubhavi Arya \\ University of Minnesota, Twin Cities \\ Minnesota, United States
}

\begin{abstract}
This article is centered around the sort of virtual reality (VR) - MoCap - motion capture. VR is utilized as a part of the planning and design procedure of the working environment. Firstly, the work environment is designed and before actual building the various conditions are simulated. Product of this simulation by VR is the working environment/ building. VR is utilized too in the medical treatments. This paper investigates a way to deal with physical rehabilitation using best in class advances in virtual reality and motion tracking. As of present, there has been a boom in the utilization of the Kalman channel in Virtual/ Augmented Reality. This paper presents a brief introduction to the Kalman filter and the development of the utilization of the filter in VR motion tracking.
\end{abstract}

Keywords: Motion, tracking, virtual reality, VR, Motion capture, MoCap

\section{INTRODUCTION}

This article is centered on the sort of virtual reality (VR) MoCap - motion capture. Motion capture is the technique of recording patterns of client's movement digitally and the interpretation of these movements into the developments of advanced digital model.

In the recent years, video games advancements and technologies are quickly developing by changing the way clients interact with the game. Some of these technologies, which are changing the gaming worldview, are motion tracking and virtual reality. Motion trackers began to show up in the gaming business in the mid 2000s, with products, for example, the EyeToy for PlayStation. Later in the decade, there was an imperative development in the amount of games where the client required a more direct interaction with the console as opposed to simply pressing buttons in a controller, for example, moving their bodies in certain approaches to accomplish objectives. ${ }^{5}$ The absolute most regular gadgets responsible for recording and tracking the client movements were the WiiMote, Wii MotionPlus and Wii Balance Board from Nintendo, Kinect from Microsoft and the PlayStation Move and Eye from Sony. Every one of these gadgets utilize diverse technologies to accomplish a comparative objective, by means of camcorders, pressure sensors, depth sensors, gyroscopes, accelerometers, and so on. Sometimes, games involving motion tracking are called active games, and the reality of playing these is regularly referred as exergaming, and to the date a few researchers have investigated the benefits of this practice. ${ }^{28-34}$

Regarding virtual reality, it is really an old idea, as the term goes back to the 1980s and the idea and the technology existed years before. ${ }^{35}$ However, late advances accomplishing a satisfactory level of virtual reality are presently beginning to become mainstream, ${ }^{39}$ as gadgets, for example, Oculus Rift are creating extraordinary expectations and its cost is currently affordable for a lot of clients. Additionally, there is expanding enthusiasm from the academic group in this area, as it can be seen in the organization of recent sessions, for example, the one from IEEE based this topic. ${ }^{36}$ Moreover, there are broad and various number of fields other than gaming where virtual reality can be connected, for example, education or military training among numerous others.5 However, one of the areas where the use of virtual reality turns out to be all the more promising is medicine, as medical specialists and students have been utilizing virtual reality for performing simulations of surgery interventions, ${ }^{37}$ and lately this area is incorporating virtual reality gadgets for patients.

Secondly, in today's time organizations frequently need to simulate some natural events, for example, individuals strolling or moving a few things from some place to another. The organizations regularly need to recreate/simulate some working environment before the real building. For this reproduction, the virtual reality (VR) is flawless solution. At the beginning the workplace is modelled and different conditions are simulated before its real building which makes provision for ergonomic requirements, because a badly designed workplace increases additional costs and assembling time. ${ }^{8}$ As of now most organizations endeavor to set up the projects of new items by reenactments/ simulations and investigation and not on presumptions or conjecture. Personnel are moving among virtual machines and monitor their location. 8 In the case of a new idea, plan 
is reconditioned and the client is moving to the new area again. If the manufactory is optimally designed, then realization its building starts. 8 VR has in these stages a very imperative part as there are substantial financial savings. The outcomes are working environments, which influence arrangement for demand and thus these working environments help to avoid for tiredness of laborers and subsequently for sickness from work and it reduces fluctuation of workers and so the costs for training of new workers. The manual assembling is simulated in ergonomical angles as well, for instance whether the laborer will have enough space for the hands and assembled components and whether he will have a decent view for the activity (Figure 1). This technology is for the most part utilized for car and aviation industries. , $^{2,9-13,22}$

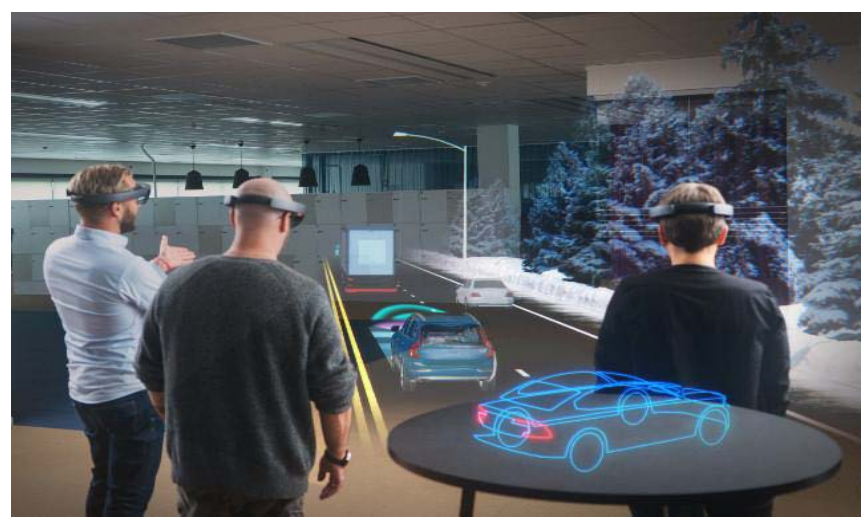

Figure 1. VR in designing the assembly process of a $\operatorname{car}^{26}$

\section{REVIEW OF LITERATURE}

\section{Human Motion Tracking for Virtual Reality}

As VR is innately an interactive paradigm, a basic piece of most VR frameworks is the online, real-time, constant estimation of human movement-essentially head movement-with the end goal of creating head-coupled synthetic imagery. For most applications, head tracking is viewed as more vital than stereo imagery. To cite Sutherland, "Although stereo presentation is important to the three-dimensional illusion, it is less important than the change which takes place in the image when the observer moves his head. The image presented by the threedimensional display must change in exactly the same way which the image of a real object would change for similar motions of the user's head. Psychologists have long known that moving perspective images appear strikingly threedimensional even without stereo presentation.” 54

Presenting computer-generated imagery that changes "exactly the same way that the image of a real object would change" translates into very demanding requirements for the accuracy, resolution, and speed (low latency and high update rate) of the head tracking and image generation. ${ }^{53}$ The issue is that we people have a lifetime of involvement with visual, vestibular, and proprioceptive correspondences, and even the scarcest discernible deviations can bring about a break in the client's feeling of presence in the virtual world, or more terrible, sickness.

The difficulties are considerably more greater for augmented reality (AR), where computer graphics images are mixed with a client's perspective of the real world. Misregistration can be confusing or distracting, for applications such as AR-assisted surgery. ${ }^{53}$ The present frameworks regularly employ client-worn components the size of a golf ball or smaller, and can accomplish head position accuracy and resolution of tenths of millimeters, and orientation accuracy and resolution of hundredths of degrees, all with latencies on the request of milliseconds.

While the reasons for visual mistake in interactive computer graphics frameworks are various, the errors originating in the tracking framework have a tendency to dominate every single other source. In Rich Holloway's 1995 Ph.D. paper, he altogether broke down the sources of error in an augmented reality (AR) framework for computer supported surgical planning55. He inferred that error in head tracking is the real reason for registration error in AR frameworks, and that inactivity is one of the essential drivers of error in head tracking. His investigation is still suitable today, and will be for a long time to come, given the principal idea of it.

The sources of error in a tracking system are typically described as static or dynamic. As for the previous, there are ordinarily a few parts between which static geometric changes must be evaluated preceding utilization of the framework. Cases would be the six degree-of-freedom (6 DOF) transform from a laboratory coordinate system to that of the tracking system, and the 6 DOF change from a headworn tracker sensor to the client's eyes. Contingent upon the separation distances and angles included, the error amplification can be nontrivial.

Specialists continue to study the effect of system latency on VR frameworks; but, given the inconceivability of lessening the inactivity to zero, motion prediction plans proliferate. In fact, as opposed to fusion or filtering, it is the issue of motion prediction that gave rise to the earliest utilization of the Kalman filter in human motion tracking for virtual reality. Many years passed before VR specialists understood that the Kalman filter is maybe the ideal device for exquisitely combining multisensor filtering, fusion and motion prediction in a solitary quick and exact structure. 
2. NEW SOFTWARES AND DEVICES FOR MOTION TRACKING IN VIRTUAL REALITY IN INDUSTRIAL APPLICATIONS

\subsection{FIRST CASE OF MOTION TRACKING}

\section{A. Device - ARTrack2}

ARTrack2 is a passive framework, which utilizes detached inflexible body targets. These markers are back mirroring the approaching IR radiation into the direction of the approaching light. These markers are for the most part spheres secured with retro reflecting foils, yet can likewise be stickers produced using retro reflecting material. This passive framework does not require wearing wires or electronic gadgets from client. Markers are typically connected straightforwardly to the client. ${ }^{24}$

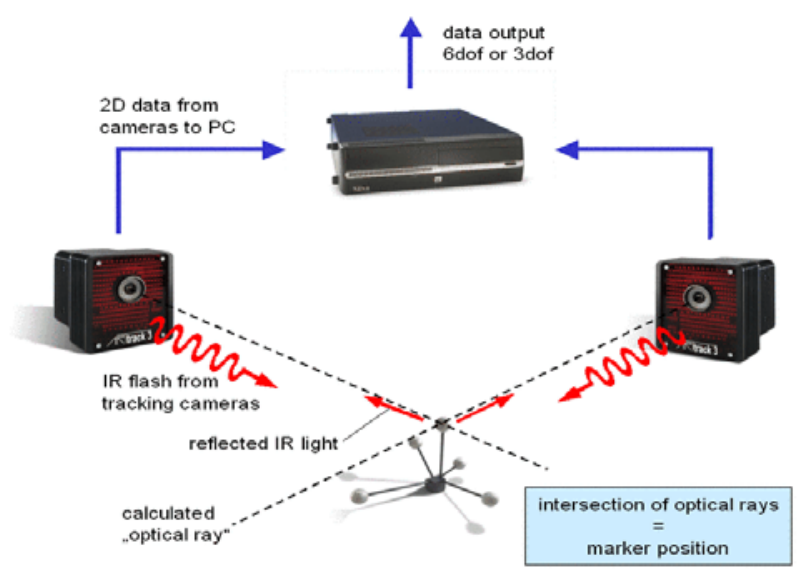

Figure 2. The ART Setup ( Principle of Passive Targets) ${ }^{24}$

The calibration of targets is quick and straightforward. The recognizable proof of a rigid body depends on the separations between single markers in a target. This implies that each target needs to demonstrate a novel arrangement of marker distances. ${ }^{24}$ For head tracking in passive stereo frameworks, tracking targets must be fixed to the stereo glasses and different targets are joined straightforwardly to the client.

\section{B. Software - Virtools}

One of the numerous software products utilized for 3D visualization is Virtools (Figure 3). In figure 3, there is the fundamental section of this software interface - graphic window with 3D models on the left side, hierarchy manager on the right side and window for creating graphic script is placed down. This product permits fast and simple creation of a virtual world. The creation of models in Virtools isn't possible, however simple components, for example, cameras, lights, rooms and standard media, like pictures, sounds, animations and models can be made with the click of a button in Virtools Resources. ${ }^{8}$ It is basic programming software, which utilizes the production of graphics script to make behaviours of components from virtual world. It is easier for a client like using a text script. ${ }^{19}$

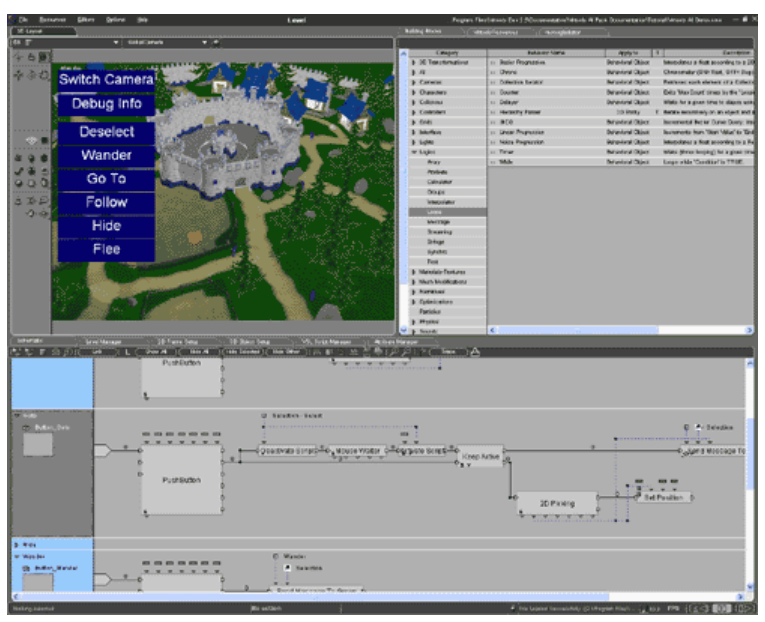

Figure 3. Virtools ${ }^{27}$

\section{The use of ARTrack2 and Virtools}

This case demonstrates how ARTrack2 and Virtools can be utilized for motion tracking. This case presents motion in the virtual corridor, which is same like when a client is moving. When conditions of designed hall are tested after the real building, it is exceptionally valuable. The production hall with various devices is modelled in ProEngineer system. ${ }^{8}$ After optical system starts, the calibration of this system is running. Then the "walking" in virtual production hall is possible. ${ }^{8}$ When the client stands on the place, where the calibration was performed, in the virtual hall the client stands too.8 In this way, the direction in which the client is moving, in the virtual world he is moving in a similar way. At the point when the client is close to the calibration position, his speed of walking in the virtual world is moderate and when he is further, his speed is quicker. So the client can try some properties of new designed hall, for example location of machines and he can try, whether will have enough place for the crossing among machines with a material. ${ }^{8}$

In this arrangement, when the client doesn't move, in the virtual production hall he is moving constantly. In the event that the client needs to remain in the virtual world, he needs to go back - on the calibration place. It is a decent arrangement, however more costly. In this illustration client can attempt to use the virtual worker and he can control with its hands and attempt that the virtual worker has enough place for assembly procedure of parts - for body, how is the view on the segments.

\subsection{SECOND CASE OF MOTION TRACKING}

\section{A. Device - Polhemus Patriot}

Patriot is the cost-effective solution for 6 DOF motion tracking. It's an expandable framework that can 
accommodate up to two sensors, making ideal for a wide array of uses. Patriot provides dynamic, real-time measurements of position (X, Y and $\mathrm{Z}$ Cartesian coordinates) and orientation (azimuth, elevation and roll). ${ }^{23}$

Patriot includes a system electronics unit (SEU), a power supply, one sensor and one source (Figure 4). The system's capabilities can be expanded by simply adding an additional sensor or an optional stylus. ${ }^{23}$

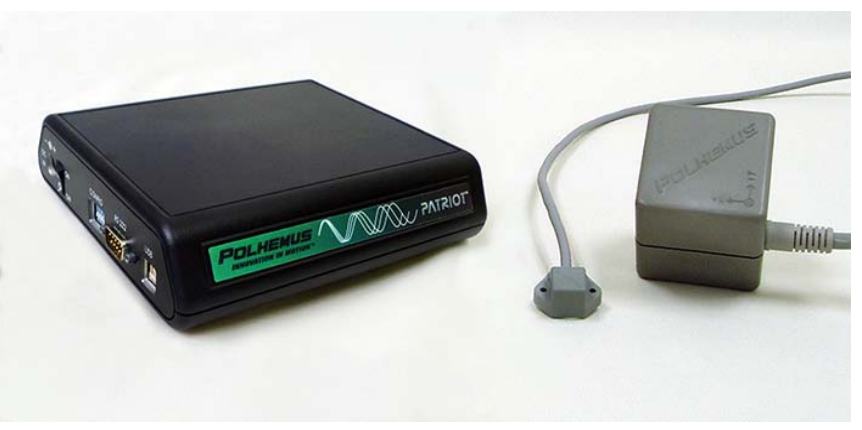

Figure 4. Polhemus Patriot

\section{MEDICAL APPLICATIONS OF MOTION} TRACKING

Scholarly enthusiasm for applying new innovations in the medical field has essentially expanded in the current years. This segment investigates related work where advances, for example, virtual reality or motion tracking are utilized for medical applications, including physical recovery.

The utilization of virtual reality to the fields of rehabilitation and treatment has been analyzed for a long time, and 10 years prior it was developing fundamentally. This reality prompted the distribution of a SWOT investigation of this topic ${ }^{40}$, which uncovered it to be a promising territory for the coming years. Some current works uncover a few uses of virtual reality to physical rehabilitation, for example, the utilization of Oculus Rift glasses during occupational therapy in kid patients with burn wounds to decrease the torment of the treatment. ${ }^{1}$

Besides, a vital preferred standpoint of virtual reality is that it can be utilized to upgrade the advancement of proprioception, which in the meantime can have extra points of interest. The idea of presence and awareness in virtual reality frameworks was investigated in the early-and mid2000s. ${ }^{3,6}$ Medical applications for this principle have been investigated in the current years with research works including lessening phantom limb pain,, ${ }^{74}$ gaining useful abilities in patients with cerebral paralysis, ${ }^{21}$ accomplishing upper limb rehabilitation of stroke patients ${ }^{26}$ and enhancing balance and postural stability in patients with diabetic peripheral neuropathy. ${ }^{17}$ Also, the use of virtual reality in neuroscience has been lately explored. ${ }^{38}$
With respect to motion tracking, medical applications were investigated in the institute not long after the first devices showed up in the 1980s. ${ }^{15}$ By far, the most widely recognized device inside this examination field is Microsoft Kinect, which has been utilized for an assortment of applications including appraisal of postural control, 18 assessment of foot posture, ${ }^{16}$ identifying anterior cruciate ligament injury risk ${ }^{20}$ and again for in-clinic and in-home physical rehabilitation ${ }^{41,42}$ and for upgrading portability and diminishing the danger of falling with gait tracking. ${ }^{43}$ Besides Kinect, Leap Motion has additionally been utilized for hand rehabilitation, ${ }^{44}$ and particular gadgets, for example, smart gloves have been created for enhancing hand and upper extremity function. ${ }^{45}$ The utilization of other motion tracking tools for physical rehabilitation has additionally been surveyed, ${ }^{46}$ and in cases as preventing cognitive decline results better results than with conventional exercise have been achieved. ${ }^{47}$ Finally, the mix of motion tracking and virtual reality for physical rehabilitation has likewise been investigated.

Another way to deal with physical rehabilitation of the right shoulder's rotator cuff joins immersive virtual reality utilizing Oculus Rift DK2 goggles and motion tracking utilizing Intel RealSense. ${ }^{5}$ These gadgets was both released in the second half of 2014, so they can be considered best in class advances in their separate fields. A soccer game has been created where the patient plays the part of the goalkeeper, and needs to stop the balls that are shot with certain recurrence and height (angle), keeping in mind the end goal to perform shoulder adduction and abduction movements. The motion tracking device performs tracking of the position of the upper body skeleton and the game increases the patient's score if the movement is performed accurately (in which case, the ball will be stopped).

As the patient wears the virtual reality glasses, he can't see his surrounding environment, which is replaced by a virtual soccer field. Additionally, the patient is just able to see the position of his hand, but not whatever is left of his body, neither one of the arm. This improves the impacts of proprioception, as the patient must perform an extra effort to do the required movements in the correct way, keeping the storage compartment straight and the arm totally expanded.

Finally, four experts tried and evaluated the game, concluding that it shows promising results for the sake of shoulder rehabilitation, pointing out that an expert should supervise at least the first session. ${ }^{5}$ 


\section{THE USE OF KALMAN FILTER FOR HUMAN MOTION TRACKING IN VIRTUAL REALITY}

\subsection{The Kalman Filter}

The Kalman filter is a set of mathematical equations that provides an efficient computational means to recursively estimate the state and error covariance of a process, in a way that minimizes the mean of the squared error covariance. ${ }^{53}$ The Kalman channel is powerful in a few aspects: it supports estimations of past, present, and future states, and it can do so even notwithstanding when the state components are hidden, or the exact idea of the modeled framework is obscure. It is ideal as in the sense that gain $\mathrm{K}$ limits the trace of the error covariance, when the procedure, estimation, and noise models are proper. A more entire clarification of the Kalman channel is past the extent of this paper. The peruser is urged to counsel one of the many books or papers describing the filter, for example, Gelb (1974); Welch and Bishop (1995); Brown and Hwang (1996).

\subsection{Kalman Filter for Motion Tracking}

Beyond head, hand, and device tracking, there has been some interesting Kalman filter based motion capture work, some of which has discovered its way into commercially accessible items. Motion-capture frameworks are utilized to get dynamic kinematic models of moving humans (for instance, for motion studies or motion picture making). A generally famous approach is optical motion capture. The subjects wear dark black Lycra suits with golfball-sized retroreflective spheres joined everywhere. Uncommon infrared (IR) cameras with IR ring lights enlighten the scene and measure the $2 \mathrm{D}$ picture coordinates of the spheres, and in software the frameworks estimate the dynamic stance of the moving bodies. However, optical motion capture is presently making space for inertial frameworks (all utilizing Kalman filters) which are eliminating the need for infrastructure, enabling the client's movement to be caught past the lab, outside-for all intents and purposes anyplace.

Intriguing work on this was initially pursued by Eric Bachmann at the U.S. Naval Postgraduate School in 2000. Bachmann built custom small devices which included magnetometers and inertial sensors (angular rate gyros and linear accelerometers). He appended the devices to different points on the client's body, and after that utilizing Kalman filters and a kinematic model of the body (for earlier requirements), he could record human movement with no cameras ${ }^{53}$. Around that same time, Shin, Lee, Shin, and Gleicher (2001) and Tak, Song, and Ko (2002) were utilizing the Kalman filter to help in on-or off-line interpretation of motion capture data. Luinge and Veltink (2005) utilized the Kalman filter to help evaluate the orientation of human body portions utilizing inertial sensors yet no magnetometers. To get an absolute reference for pitch and roll (not heading) they quantified the gravity vector utilizing accelerometers, and after that consolidated this with the incorporated yields of gyrators utilizing an errorstate (or integral) Kalman filter. In this way the accelerometers served as a guide to the framework, by giving a free measure of the gravity vector, which is utilized to help control orientation drift. This is like some prior work by Foxlin (1996). All the more as of late, Daniel Vlasic and his colleagues utilized a comparative approach; but, they utilized time-of-flight acoustic ranging to constrain the distances between the sensors, thus improving the robustness and accuracy of the captured motion ${ }^{53}$.

Commercially, a business called Animazoo has built up an inertial motion capture framework that utilizes 3 DOF InertiaCube rotation sensors from InterSense mounted on every limb to evaluate the dynamic explained body models. Another business, called Xsens, has built up an inertial motion capture suit from the beginning, with custom inertial sensors. Xsens's Moven framework utilizes Kalman filters to track the position and orientation of each body fragment in view of custom sensors that incorporate linear accelerometers and angular rate gyros, making possible the capture of horizontal and vertical movement, for example, running and jumping.

\section{CONCLUSION}

As of now, virtual reality technology is most utilized as a part of the car and aviation ventures and industries. The organizations regularly need to simulate some working environment before the actual building. For this simulation, the virtual reality (VR) is the ideal arrangement. With this framework client can try to walk in the virtual production hall; and can check whether the space among machines is sufficiently huge for specialists and for traverse with material among these machines. Toward the starting the work environment is modelled and distinctive conditions are reproduced before its actual building. In the event that the manufactory is palatably designed, at that point acknowledgment and realization of its building begins. VR is utilized as a part of the design procedure, as well. In the event that the entire procedure of designing and planning of product is designed, controlled and simulated with help of virtual reality, in the manufacturing and assembling procedure there ought not be numerous more serious issues. This framework tracks the client's developments and accordingly the virtual user performs same movements like the client. With the assistance of these applications the organizations can attempt these conditions and thus save their monetary and financial resources. 


\section{ACKNOWLEDGEMENT}

I would like to acknowledge the teaching support and guidance of Ms. Victoria Interrante and Dan, College of Science and Engineering, University of Minnesota, USA.

\section{REFERENCES}

1. Tarr MJ, Warren WH. Virtual reality in behavioral neuroscience and beyond. Nature Neuroscience. 2002;5:108992.

2. G. C. Burdea, P. Coiffet, "Virtual Reality Technology", Second Edition, New Jersey: John Wiley\&Sons, Inc., 2003, p. 424, ISBN 0-471-36089-9.

3. Sanchez-Vives MV, Slater M. From presence to consciousness through virtual reality. Nature Rev Neuroscience. 2005;6:332-9.

4. V. Fečová, "Optical motion tracking used in the virtual reality systems”, CEURSIS 2010: the International Conference of the Carpathian Euro-region Specialists in Industrial Systems, Baia Mare, 2010, pp. 81-86, ISBN 978-606-536-094-5.

5. Baldominos, Alejandro, et al. "An Approach to Physical Rehabilitation Using State-of-the-Art Virtual Reality and Motion Tracking Technologies.” Procedia Computer Science, vol. 64, 2015.

6. Zweighaft AR, Slotness GL, Henderson AL, Osborne LB, Lightbody SM, Perhala LM, Brown PO, Haynes NH, Kern SM, Usgaonkar PN, Meese MD, Pierce S, Gerling GJ. A virtual reality ball grasp and sort task for the enhancement of phantom limb pain proprioception. In: SIEDS 2012. Proceedings of the 2012 Systems and Information Design Symposium; 2012 Apr 27; Charlottesville, VA, USA. P. 17883.

7. Monge E, Molina F, Alguacil IM, Cano R, De Mauro A, Miangolarra JC. Use of virtual reality systems as proprioception method in cerebral palsy: clinical practice guideline. Neurología (Eng Ed). 2014;29(9):550-9.

8. Fečová, Veronika, et al. "Devices and Software Possibilities for Using of Motion Tracking Systems in the Virtual Reality System ." 2012 IEEE 10th International Symposium on Applied Machine Intelligence and Informatics (SAMI), 26 Jan. 2012.

9. I. Kuric, J. Novák-Marcinčin, R. Cotetiu, N. Ungureanu, "Development of Progressive Technologies - Computer Support for Progressive Technologies”. Vienna, 2007, p. 253, ISBN 3- 901509-28-3.

10. J. Novák-Marcinčin, "Theory and practice of virtual manufacturing”, Manufacturing Engineering, 2/2007, pp. 8591, ISSN 1335-7972. http://web.tuke.sk/fvtpo/journal/index.htm

11. J. Novák-Marcinčin, P. Brázda, M. Kuzmiaková, V. Fečová, "Some aspects of manufacturing workplaces simulation by virtual reality”, IN-TECH 2010, International Conference on Innovative Technologies, Prague, Czech Republic, Praha: Jan Kudláček, 2010, pp. 177-179, ISBN 978-80-904502-2-6.

12. J. Novák-Marcinčin, V. Fečová, "The applications of virtual reality in the automotive industry", New Ways in Manufacturing Technologies 2010: 10th international scientific conference, Prešov, Slovakia, Prešov: FVT TU, 2010, pp. 423-428, ISBN 978- 80-553-0441-0.
13. J. Novák-Marcinčin, V. Fečová, "The options of motion tracking in the virtual reality systems”, TMT 2010: 14th International Research/Expert Conference Trends in the Development of Machinery and Associated Technology, Mediterranean Cruise, Vol. 14, no. 1., 2010, pp. 361-364, ISSN 1840-4944.

14. Snow PW, Loureiro RCV, Comley R. Design of a robotic sensorimotor system for Phantom Limb Pain rehabilitation. In: BioRob 2014. Proc. of the 2014 5th IEEE RAS \& EMBS Int. Conf. on Biomedical Robotics and Biomechatronics; 2014 Aug 12-15; Sao Paulo, Brazil. P. 120-5.

15. Clark RA, Pua YH, Fortin K, Ritchie C, Webster KE, Denehy L, Bryant AL. Validity of the Microsoft Kinect for assessment of postural control. Gait \& Posture. 2012;36(3):372-7.

16. Gray AD, Marks JM, Stone EE, Butler MC, Skubic M, Sherman SL. Validation of the Microsoft Kinect as a portable and inexpensive screening tool for identifying ACL injury risk. Orthopaedic J Sports Med. 2014;2(2).

17. Bohil CJ, Alicea B, Biocca FA. Virtual reality in neuroscience research and therapy. Nature Rev Neuroscience. 2011;12:75262

18. Mentiplay B, Clark R, Bryant A, Bartold S, Paterson K. Evaluation of foot posture using the Microsoft Kinect. J Sci Med Sport. 2013;16(S1):e24-5.

19. “Virtools Dev User Guide Download.” Virtools Dev User Guide, manualzilla.com/doc/6922972/virtools-dev-userguide?page $=215$.

20. Chang CY, Lange B, Zhang M, Koenig S, Requejo P, Somboon N, Sawchuk AA, Rizzo AA. Towards pervasive physical rehabilitation using Microsoft Kinect. In: PervasiveHealth 2012. Proceedings of the 2012 6th International Conference on Pervasive Computing Technologies for Healthcare; 2012 May 21-24; San Diego, CA, USA. P. 159-62

21. Cho S, Ku J, Cho YK, Kang YJ, Jang DP, Kim SI. Development of virtual reality proprioceptive rehabilitation system for stroke patients. Comp Methods Progr Biomed. 2014;113(1):258-65.

22. "Motion Capture." Wikipedia, Wikimedia Foundation, 16 Oct. 2017, en.wikipedia.org/wiki/Motion_capture.

23. "Patriot ${ }^{\mathrm{TM}}$." Polhemus Patriot, polhemus.com/motiontracking/all-trackers/patriot.

24. deflektor.de. “ART Advanced Realtime Tracking.” ART Advanced Realtime Tracking, www.ar-tracking.de/.

25. www.worldviz.com/products/vizard4/index.htm.

26. Grewal GS, Sayeed R, Schwenk M, Bharara M, Menzies R, Talal TK, Armstrong DR, Najafi B. Balance rehabilitation. J American Podiatric Med Assoc. 2013;103(6):498-507.

27. "Virtools $\quad 3.0 \quad$ Review." Gamesgreggmancom, games.greggman.com/game/virtools_3_0_review/.

28. Klein M, Simmers C. Exergaming: virtual inspiration, real perspiration. Young Consumers. 2008;10(1):35-45.

29. Daley A. Can exergaming contribute to improving physical activity levels and health outcomes in children. Pediatrics. 2009;124(2):763-71.

30. Maddison R, Foley L, Mhurchu C, Jiang Y, Jull A, Prapavessis H, Hohepa M, Rodgers A. Effects of active video games on body composition: a randomized controlled trial. Am J Clin Nutr. 2011;94(1):156-63. 
31. 4. O’Loughlin E, Dugas E, Sabiston C, O’Loughlin J. Prevalence and correlates of exergaming in youth. Pediatrics. 2012;130(5):806-14.

32. Peng W, Crouse J, Lin J. Using active video games for physical activity promotion: a systematic review of the current state of research. Health Educ Behav. 2013;40(2):171-92.

33. Bochner R, Sorensen K, Belamarich P. The impact of active video gaming on weight in youth: a meta-analysis. Clin Pediatr. 2015;54(7):620-8.

34. Tate D, Lyons E, Valle C. High-tech tools for exercise motivation: use and role of technologies such as the Internet, mobile applications, social media, and video games. Diabetes Spectrum. 2015;28(1):45-54.

35. Steuer J. Defining virtual reality: dimensions determining telepresence. J Commun. 1992;42(4):73-93.

36. Coquillart S, Kiyokawa K, Swan JE, Bowman D, editors. Proceedings of the 2014 IEEE Virtual Reality (VR); 2014 Mar 29-Apr 2; Minneapolis, MN, USA. Danvers: IEEE; 2014.

37. Oculus Rift DK2 Virtual Reality Headset [Internet]. 2015 [cited 2015 Mar 15]. Available from: https://www.oculus.com/dk2/

38. Zhou H, Hu H. Human motion tracking for rehabilitation - a survey. Biomed Signal Proc Control. 2008;3(1):1-18.

39. Avila L, Bailey M. Virtual reality for the masses. IEEE Comp Graph Appl. 2014;34(5):103-4.

40. Hoffman HG, Meyer WJ, Ramirez M, Roberts L, Seibel EJ, Atzori B, Sharar SR, Patterson DR. Feasibility of articulated arm mounted Oculus Rift virtual reality goggles for Adjunctive Pain Control during occupational therapy in pediatric burn patients. Cyberpsych Behavior Soc Netw. 2014;17(6):397-401.

41. Tao G, Archambault PS, Levin MF. Evaluation of Kinect skeletal tracking in a virtual reality rehabilitation system for upper limb hemiparesis. In: ICVR 2013. Proc. of the 2013 Int. Conf. on Virtual Rehabilitation; 2013 Aug 26-29; Philadelphia, PA, USA. P. 164-5.

42. Gaukrodger S, Peruzzi A, Paolini G, Cereatti A, Cupit S, Hausdorff J, Mirelman A, Della Croce U. Gait tracking for virtual reality clinical applications: a low cost solution. Gait \& Posture. 2013;37(S1):S31.

43. Charles D, Pedlow K, McDonough S, Shek K, Charles T. Close range depth sensing cameras for virtual reality based hand rehabilitation. J Assistive Tech. 2014;8(3):138-49.

44. Sivak M, Murray D, Dick L, Mavroidis C, Holden MK. Development of a low-cost virtual reality-based smart glove for rehabilitation. In: Sharkey $\mathrm{P}$, Klinger $\mathrm{E}$, editors.
ICDVRAT 2012. Proc. of the 9th Int. Conf. on Disability, Virtual Reality and Associated Technologies; 2012 Sep 1012; Laval, France. Reading: UK; 2012. P. 279-86.

45. Koenig S, Ardanza A, Cortes C, De Mauro A, Lange B. Introduction to low-cost motion-tracking for virtual rehabilitation. In: Pons JL, Torricelli D, editors. Emerging therapies in neurorehabilitation. Springer; 2014. P. 287-303. (Biosystems \& biorobotics; vol. 4).

46. Anderson-Hanley C, Arciero P, Brickman A, Nimon J, Okuma N, Westen S, Merz M, Pence B, Woods J, Kramer A, Zimmerman E. Exergaming and older adult cognition: a cluster randomized clinical trial. Am J Preventive Med. 2012;42(2):109-19.

47. Lange B, Koenig S, Chang CY, McConnell E, Suma E, Bolas M, Rizzo A. Designing informed game-based rehabilitation tasks leveraging advances in virtual reality. Disability and Rehabilitation. 2012;34(22):1863-70.

48. Rizzo A, Kim G. A SWOT analysis of the field of virtual reality rehabilitation and therapy. Presence. 2005;14(2):11946.

49. J. Barna, V. Fečová, M. Janák, "Power tool for development environment for creation of 3D real-time applications", Journal of Engineering and Technology for Young Scientists, Vol. 1, No. 1, 2010, pp. 5-10, ISSN 1338-2349.

50. V. Fečová, "The principle of the active and passive markers of optical motion tracking for the virtual reality systems”, New Ways in Manufacturing Technologies 2010: 10th international scientific conference, Prešov, Slovakia, Prešov: FVT TU, 2010, pp. 145- 152, ISBN 978-80-553-0441-0.

51. S. K. Ong, A. Y. C. Nee, "Virtual and Augmented Reality Applications in Manufacturing”, London: Springer, 2004, p. 388, ISBN 1-85233-796-6.

52. W. R. Sherman, A. B. Craig, "Understanding Virtual Reality. Interface, Application, and Design”, San Francisco: Elsevier Science, 2003, p. 583, ISBN 1-55860-353-0.

53. G. F. Welch, "HISTORY: The Use of the Kalman Filter for Human Motion Tracking in Virtual Reality," in Presence, vol. 18, no. 1, Feb. 12009 doi: 10.1162/pres.18.1.72 URL: http://ieeexplore.iee.org/stamp/stamp.jsp?tp=\&arnumber=67 97722\&isnumber $=6797157$

54. Sutherland, I. E. (1968). A head-mounted three dimensional display. Proceedings of the 1968 Fall Joint Computer Conference, AFIPS, Vol. 33, Part 1, 757-764

55. Holloway, R. L. (1995). Registration errors in augmented reality systems. Ph.D. thesis, University of North Carolina at Chapel Hill. 